\title{
Huerto cerrado, de Alfredo Bryce Echenique: una travesía afectuosa y divagante
}

\author{
Jorge Eslava
}

Bautizado originalmente con el nombre de uno de los cuentos del conjunto -“La vida es así"-, aparece publicado con el título de Huerto cerrado. Es el primer libro de Bryce Echenique, que luego de trazar una peripecia inusitada ${ }^{1}$ va a destacar en el concurso Casa de las Américas de 1968 y editarse ese mismo año en La Habana. Según confesión del autor, desestimó el título inicial por jactancioso ${ }^{2}$ y el definitivo se debió a la sugerencia de Julio Ramón Ribeyro.

1 Fiel a su vocación fabuladora, Bryce cuenta: “... de un coche descapotable me robaron todos los cuentos, me robaron todo lo que había hecho en Italia durante un verano maravilloso. Fue algo espantoso, al final yo no sabía si yo era el ladrón o el acusado, porque habían detenido al ladrón, pero el ladrón era otro ladrón que había pasado después y que había encontrado ya el coche vacío...". Conferencia reproducida en Cuadernos Hispanoamericanos 417. Madrid, marzo de 1985, pp. 65-76.

2 "Quería dar un mensaje a la humanidad, me imagino, porque todos los escritores cuando jóvenes creo que tenemos algo de carteros, por eso de dar mensajes...". En conferencia citada. 
Aunque puede parecer innecesario el párrafo anterior, pretende encausar con motivos paraliterarios la vocación discursiva/emotiva de este libro inaugural -tal vez de toda la obra de Bryce-, donde el tono coloquial predominante y las inflexiones de ternura y humor tienden a glorificar la memoria. Como es evidente en sus libros, el curso verbal rehúsa severos controles pues parece más atento a capturar el recuerdo que a explicar/se las circunstancias. Está siempre más próximo a la conjetura subjetiva o el devaneo, que a la certeza situacional del personaje.

Yo pertenezco -ha afirmado recientemente- a un tipo de escritor intuitivo, nada cerebral y que escribe con el sistema nervioso; que no busca, que encuentra... ${ }^{3}$

Huerto cerrado es el inicio de esa vocación retrospectiva. Se trata de un conjunto de doce cuentos enhebrados por un protagonista entrañable -Manolo, alter ego del autor-y cuya composición literaria no revela los rigores técnicos tan caros a los narradores de finales de los sesenta. Antes bien, la escritura exhibe dispersión de procedimientos e incluso una tesitura variada. Hay algo de juego, de tanteo que corresponde a los modelos literarios del entonces novel escritor: "un libro que pagaba mi tributo de lecturas desordenadas" ${ }^{4}$. Mientras que la organización de los relatos sí obedece a una estructura de lógica temporal; pues salvo el primer relato que escapa a este orden cronológico, los demás responden al crecimiento del protagonista -de los trece a los veinte años, aproximadamente-, situándose cercano a la llamada "novela de aprendizaje".

Los cuentos se inician con "Dos indios" -único relato "desobediente" a la secuencia temporal-, donde encontramos a un joven Manolo en Roma. El personaje narrador, amigo del protagonista, es

3 "La literatura consiste en crear la ilusión de la realidad". Testimonio leído el 16 de agosto de 1995 en la Facultad de Letras de la Universidad Nacional Mayor de San Marcos y publicado en la revista La Casa de Cartón, II época, núm. 18. Lima, invierno-primavera de 1999.

4 Conferencia dada en la Universidad de Texas, en Austin, el 30 de noviembre de 1982 y reproducida en la revista Cuadernos Hispanoamericanos 417. Madrid, marzo de 1985, pp. 65-76. 
quien nos informa de los cuatro años que lleva Manolo en Europa sin saber qué hacer. Concurren ambos a un café, a ver pasar la vida. Esta futilidad es pretexto para conocer a Manolo: “... triste y sombrío como un malecón en invierno -dice el narrador- (...) Entre el criollismo limeño hubiera pasado por un cojudote ${ }^{\prime \prime}$.

Es indudable que la conducta indolente del protagonista adquiere, en el desarrollo del relato, una dimensión enigmática que resulta funcional para la estructura del libro. El narrador homodiegético ha presentado al personaje eje del libro y abierto una expectativa: hay algo que lo ha quebrado, se dice el lector; existe un "dato escondido" que es preciso desentrañar. La expectativa se cumple cuando Manolo recuerda un episodio de su niñez. La evocación, acrecentada por la nostalgia, lo impulsa a tomar una decisión radical: volver al país.

-No me interesa -dijo Manolo-. Sólo me interesa regresar al Perú, y en este momento voy a una agencia de viajes para averiguar los precios.

-Yo voy a pegarme un duchazo caliente.

-Bien. Estaré de regreso dentro de una hora, y comeremos juntos. Me ayudarás a hacer las maletas.

-Sí Manolo. Y llegado el gran día, te las cargaré hasta el avión -dije, en tono burlón.

-Creo que eso también se llama exorcismo - dijo Manolo, soltando la carcajada. Ya no le quedaba tan mal reírse.] Partió.

Este diálogo se produce hacia el final de la historia y deja en claro, resuelta, la mayor angustia del protagonista, un propósito de retorno como forma de expiación. El cuento inicial realiza de este modo la doble tarea de presentarnos al personaje Manolo -con sus encantos y flaquezas- y de abrir el pórtico de la reconstrucción memoriosa, por donde va a discurrir el libro. Algo semejante al ejercicio de escritura/

5 Bryce Echenique, Alfredo. Huerto cerrado. Barcelona: Barral Editores, 1972, p. 26. En adelante usaremos esta edición.

6 La frase "dato escondido" alude a la técnica de Hemingway -autor admirado por Bryce-, que implica mostrar la superficie de un relato y ocultar o escamotear aquello que secretamente activa la historia. 
lectura del diario que realiza el narrador personaje de La casa de cartón, para fijar un "balance nostálgico de una experiencia irrescatable"7.

A partir de "Con Jimmy, en Paracas" -el segundo cuento- el lector se instala en el despertar de la adolescencia de Manolo y crece con él hasta la adultez, con la sensación de ver un álbum de fotos de tonalidad y formato diversos. En este cuento -el más celebrado del conjunto y publicado un año antes que el libro- ${ }^{8}$, el reencuentro con Manolo es motivado por un pequeño viaje al sur con su padre. Ya no es el caso anterior -él solitario en gran periplo por Europa-, sino un paseo gracias a una reunión de trabajo con los jefes de su padre, que permitirán a Manolo advertir -con crueldad y dolor- la desintegración simbólica del pater familia. La vocación de recordar y expiar el pasado, sumada a la sensación de malestar del personaje es lo que asocia esta historia a la de "Dos indios".

La desubicación permanente de Manolo, su ser disociado, es donde reside el principal encanto/desencanto del libro. Porque los diversos narradores que operan tienden veladamente a contarlo todo, desde la entraña más íntima y siempre con el favor incondicional del afecto. Veamos "Con Jimmy, en Paracas" cuando el narrador -ahora es la voz de Manolo- tiene a su padre al lado, manejando el auto tan despacio que todos van dejando atrás el viejo Pontiac:

... ya muy viejo el pobre, (que) avanzaba lentísimo, anchísimo, negro e inmenso, balanceándose como una lancha sobre la carretera asfaltada.

De estos juicios pasa a observar a su padre, a evaluarlo con rigor. Lo ve vestido con demasiado recato, con las mismas prendas de ocasiones importantes. Comprueba que es bajo y flaco. También calvo, bueno y dócil; "dócil como yo -dice Manolo-, en realidad se muere de miedo de sus jefes...". Llegado a este punto, el relato establecerá como uno de sus intereses la relación subordinada del padre con sus jefes. Bajo la mirada escrutadora de Manolo, que se ha calificado de "muy observador", el desarrollo de este mundo dividido aparece como articulado a una comedia incómoda:

7 Lauer, Mirko. Los exilios exteriores. Una introducción a Martín Adán. Lima: Hueso Húmero Ediciones, 1983, pp. 26 y 27.

8 Revista Amaru 4, octubre-diciembre de 1967. 
Fue entonces que mi padre estuvo realmente triunfal. Mientras el mozo venía con las corvinas a la no sé cuántos, mi padre empezó a hablar de darnos un lujo, de que el ambiente lo pedía, y de que la compañía no iba a quebrar si él pedía una botellita de vino blanco... En ésas estaba cuando el mozo apareció complicándose la vida en cargar los platos de la manera más difícil, eso parecía un circo, y mi padre lo miraba como si fuera a aplaudir, pero gracias a Dios reaccionó y tomó una actitud bastante forzada, aunque digna, cuando el mozo jugaba a tirarnos los platos por la cara, en realidad era que los estaba poniendo elegantemente sobre la mesa y que nosotros no estábamos acostumbrados a tanta cosa...

Un episodio posterior, que constituye el conflicto más visible, enfrenta a Manolo con Jimmy en una situación insidiosa. Jimmy es compañero de colegio de Manolo y es un chico "agrandado", que fuma, bebe y maneja carro. Pero es, sobre todo, el hijo de uno de los directores de la compañía de su padre. La conducta de ambos es manifiestamente opuesta y el relato los conduce, en una noche de copas, a una escena de insinuante homosexualidad.

Este segundo cuento no solo abre un amplio paréntesis temporal con el anterior, sino que la perspectiva y el lenguaje narrativo son distintos. Así mismo, el narrador del cuento inicial desaparece, toma la posta un narrador más cercano al personaje: el propio Manolo.

El protagonista narra este relato -y algunos posteriores- con los que irá recuperando su memoria:

Y es allí, sentado de espaldas al mar, a las rayas y a los tiburones, es allí donde lo estoy viendo, como si yo estuviera en la puerta del comedor, y es que en realidad yo también me estoy viendo sentado allí, en la misma mesa, cara a cara a mi padre...

Estas variantes técnicas además de enriquecer el acabado narrativo de Huerto cerrado, nos disponen a aceptar las historias vividas por el mismo personaje como episodios elípticos de una novela. Nuestra lectura adquiere -como en Los inocentes, libro de cuentos de Oswaldo Reynoso- cierta sensación de voluntad expansiva de los cuentos, una propensión a aproximarse a la novela fragmentada.

En los tres relatos siguientes, el narrador Manolo se distancia -en apariencia- del personaje Manolo, empleando la tercera persona gramatical para presentarnos a este en sus años de secundaria y 
enfrentado a situaciones que ponen a prueba su proceso de crecimiento. En "El camino es así", subtitulado traviesamente por el narrador: "(con las piernas, pero también con la imaginación)", Manolo tiene que superar una competencia ciclística. Logra cumplir, pero apelando más bien a la imaginación; de este modo el narrador anticipa que las cualidades del protagonista no califican por el coraje ni el esfuerzo físico, en cambio, sí por lo intelectual e ingenioso.

En "Su mejor negocio", Manolo decide vender su bicicleta al jardinero del barrio - un amigo suyo, del que empieza a tomar distancia-, para comprarse un saco de corduroy que necesita para asistir a una fiesta de amigos. La bicicleta, símbolo de su niñez, es desplazada por la "investidura" adolescente. En el siguiente cuento, "Las notas que duermen en las cuerdas" (que anticipa, como es evidente en el título, al cuento siguiente) asistimos a un relato moroso y sin anécdota; extraordinario pretexto para sopesar la prosa descriptiva del narrador e ingresar al mundo recóndito del protagonista: una individualidad pasiva, temerosa y profundamente personal. Aquí la doble visión del narrador - del paisaje urbano burgués y del personaje Manolo-, encuentra un punto de confluencia con La casa de cartón:

Pronto los ternos de verano recién sacados del ropero, dejarán de oler a humedad. El sol brilla sobre la ciudad, sobre las calles, sobre las casas. Brilla en todas partes menos en el interior de las viejas iglesias coloniales. Los grandes almacenes ponen a la venta las últimas novedades de la moda veraniega. Los almacenes de segunda categoría ponen a la venta las novedades de la moda del año pasado. "Pruébate la ropa de baño, amorcito". (¡Cuántos matrimonios dependerán de esa prueba!).

Se advierte, desde luego, el espíritu socarrón y el lenguaje puntilloso, compuesto de periodos cortos y con abundancia de enumeraciones. Aunque no posee el temblor lírico del relato de Martín Adán, consideramos que este cuento se inscribe en esa orientación descriptiva y minuciosa de la ciudad, revelando su dinámica de cambio social. Pero además el narrador escruta el paisaje $-y$ a sus habitantes- con una vena sutilmente corrosiva:

Amada, la secretaria del doctor Ascencio, abogado de nota, casado, tres hijos, y automóvil más grande que el del vecino, ha dejado hoy, por primera vez, la chompita en casa. Ha entrado a la oficina, y el doctor ha bajado la mirada: en la moda del escote "ecran", un escote que parece un frutero. “Qué linda su medallita Amada (el doctor lo ha oído decir en la 
calle). Tengo mucho, mucho que dictarle, y tengo tantos, tantos deseos de echarme una siestecita".

La voz del narrador en este cuento, en tercera persona, nos da luces sobre el interior del protagonista -como veremos más adelantey además, en un acertado uso narrativo de vasos comunicantes, establece vínculos con el último episodio del libro. Como un ejercicio distraído, en la laxitud de esos días previos a la Navidad, nos provee de información sobre las raras aficiones de Manolo: salir a caminar y contar puertas y ventanas, para luego anotar el número en una libreta sin ninguna razón aparente. El narrador califica estas acciones de "extraña sumersión" y "extraño paseo", acciones que serán el leit motiv del cuento final llamado "Extraña diversión".

Transcurrido el mes de diciembre en "Las notas que duermen en las cuerdas" -mes simbólico: encuentro familiar, despedida de colegio-, en el relato siguiente Manolo inicia sus vacaciones de verano y en éstas su descubrimiento del amor. El título "Una mano en las cuerdas" alude al despertar de las fibras íntimas -el entusiasmo, la pasión- aletargadas en el cuento anterior ${ }^{9}$. Ahora la perspectiva adquiere la oscilación de dos voces narrativas.

El desdoblamiento del narrador en dos instancias, no excluye técnica ni emocionalmente una instancia de otra. La proximidad de voz y personaje en varios momentos de las historias, da la apariencia de un narrador jugando a las escondidas, pues la distancia del punto de vista tiende a manifestarse/ocultarse. Como sucede en "Una mano en las cuerdas", donde la estrategia narrativa es el diario, que implica una tonalidad más íntima mediante la escritura en primera persona, efectuada por el autor del diario. Este personaje es Manolo, en sus quince años, pero la presencia de "otro" narrador -en oposición a Manolo- es notoria:

17 de febrero

Soy el hombre más feliz de la tierra. Cecilia. ¡Cecilia! No puedo escribir. No podré dormir. ¡No importa!

9 Como la célebre "Rima VII" de Bécquer: “Cuánta nota dormía en sus cuerdas / como un pájaro duerme en las ramas, / esperando la mano de nieve / que sabe arrancarlas!". 
No se hizo esperar. A las 3.30, en punto, Manolo la vio descender del automóvil de sus padres, en la puerta del cine...

En el cuento grotesco y brutal que es "Yo soy el rey", se retoman elementos de sexualidad que descolocan nuevamente al protagonista, refugiándolo en una conciencia asustadiza y secreta. Aunque Manolo está en las mismas arenas movedizas del sexo, no es el ámbito de la hipotética homosexualidad de "Con Jimmy, en Paracas", ni del enamoramiento platónico que experimentó en el pasado con "Una mano en las cuerdas", ni el trance erótico del episodio siguiente en "Descubrimiento de América", sino la exploración del mundo sórdido del prostíbulo y de su fauna esperpéntica.

Es en este ámbito que se desarrolla la historia de iniciación sexual de Manolo, su "estreno" auspiciado por los amigos y ante el cual nuestro personaje cede resignadamente. En el cuarto del burdel, su experiencia es frustrante: la estampa de un santo pegada a la pared, al lado de una Miss Universo es todo lo que logra ver y son ambas imágenes símbolos de dos mundos que jalonan su vida.

El cuento "Descubrimiento de América" aborda el tema sexual de pareja, haciendo una elipsis por el tema amoroso. Manolo es ahora un estudiante universitario y cree estar enamorado de América. Ella es, sin embargo, su antípoda:

... [una] colegiala que ya se cansó de serlo... colegiala con mentalidad pre automovilística, pre lujosa, pre matrimonial... colegiala que se aburre en las clases de literatura, que jamás comprendió las matemáticas, y que piensa sinceramente que Larra se suicidó por cojudo, y no por romántico.

Esta historia está narrada por la voz del protagonista, desbaratada por el caos de sentimientos/emociones y plantea algunos equívocos, que permiten además desplegar el bagaje histriónico de Manolo; porque él está empeñado en amar y ser amado. "Amar como antes", se repite a sí mismo y conviene confrontarlo con "Una mano en las cuerdas", el cuento anterior que desarrolla una historia de amor inocente pero con un Manolo más joven. Ahora vemos al personaje ir desesperado, en pos de un deseo que su propia realidad contradice:

Sintió que la quería, y sintió también un ligero temblor en las piernas. Sin embargo, no sintió que perdía los papeles al ver que América 
bajaba del ómnibus, y eso le molestó: perder los papeles era amor para Manolo. América avanzaba. Distinguía su blusa blanca entre el chalequillo abierto de uniforme... Avanzaba. Veía ahora el bulto de sus senos bajo la blusa blanca... Te quiero tanto. Te siento. Cerca. Más cerca... Sus ojos. Buenas piernas. Pero sus ojos. La blusa... La falda con las caderas... Y América estaba a su lado. Pasaba a su lado, y su blusa se abultaba cada vez más al pasar de perfil, y ya no estaba allí, y él no volteó para no verle el culo, y porque la quería.

Como hemos señalado, no solo la estrategia del desdoblamiento del narrador a una instancia más próxima a la historia -como protagonista-, hace de este conjunto de cuentos un ejemplo notable de la narrativa de los sesenta, sino además la técnica empleada en el punto de vista. Así lo sostiene el crítico Carlos Garayar, a propósito precisamente de "El descubrimiento de América":

Este relato prefigura a algunos personajes de su narrativa posterior, en los que se combinan el amor-ternura con el cinismo, y también ciertas técnicas para cambiar el punto de vista continuamente y exige al lector una participación activa, volviéndolo cómplice: el narrador se mete dentro del personaje o hace que sea el lector el que se introduzca en el pensamiento de éste, para luego sacarlo y hacerle observar objetivamente la situación ${ }^{10}$.

En el penúltimo relato, "El hombre, el cinema y el tranvía", el narrador toma dilatada distancia y presenta a los personajes con rasgos vagos e impersonales: los de un "hombre de unos treinta años, y un muchacho de unos diecisiete o dieciocho, parados en la puerta del cine, (que) comentaban la película que acababan de ver". A través del diálogo reconocemos a Manolo como el muchacho acompañante del hombre de treinta años. La posición del narrador es flexible con la voz del personaje, ambas se entretejen para dar fluidez al relato. Tenemos entonces una instancia escindida -narrador y personaje-, descontrolada por la mano creadora de los relatos. Esa es la intención del autor implícito, quien construye el texto bajo una mirada sonriente e ingeniosa. Intención que obliga a releer el texto y descubrir nuevas voces que se desprenden de las dos instancias; voces que

10 Garayar de Lillo, Carlos. "Alfredo Bryce, narrador de cuentos". La Casa de Cartón. II época, núm. 18. Lima, invierno-primavera de 1999, p. 12. 
se yuxtaponen, se imbrican, se enriquecen. Como sucede en "Extraña diversión", el cuento que cierra el volumen, donde un narrador, en apariencia ajeno a la historia, nos cuenta las peripecias de un Manolo ¿enajenado?, ¿dislocado? Sin embargo, la voz del propio personaje "perturba" la línea del discurso:

Recogió el palo de escoba y se dejó caer de rodillas, adoptando la posición de un tirador. Apuntó con el palo de escoba... Un hueco. Basta un hueco. Les voy a abrir un hueco. Uno. Todo se chorrea por un hueco. Un hueco. Nubarrones hijos de puta... Vengan nubarrones hijos de puta. "Ta ta ta tatatatata", gritaba disparando entre la lluvia contra los nubarrones.

Es curioso que este cuento no haya llamado la atención de la crítica, por su peculiar calidad y por ser cerradura perfecta del libro. Recordemos que el viaje de regreso al Perú que decide hacer Manolo, impulsa el tránsito retrospectivo de su memoria. Evoca su pubertad con el relato "Con Jimmy en Paracas" y va reconstruyendo, en cada paso/ relato siguiente, los años de su adolescencia. Este cuento es la pieza que reclamaba el lector para completar el rompecabezas de la historia personal de Manolo. Ahora él es un personaje aparentemente mayor:

Venía de lejos. Debía venir desde muy lejos, porque su aspecto era el de un hombre fatigado; un hombre que ha caminado demasiado.

Como si hundirse en la recuperación de su memoria le hubiera tomado a Manolo mucho tiempo y, a la vez, el encuentro con su pasado le hubiera producido un quiebre emocional. Dicha ruptura se aprecia en el aislamiento del personaje con el mundo oficial de la historia -universidad, amigos, familia- y la condena de ocupar un espacio marginal. En este umbral entre dos vidas -la de la memoria y la real-, es donde el personaje aparece vagando por las calles de Magdalena -"no muy lejos del Manicomio"-, mientras efectúa con diligencia actos bastante raros: otra vez cambiar de sitio las piedras, contar puertas y ventanas de las casas y anotar cada cifra en una libreta negra ${ }^{11}$.

11 Actos ya anunciados en el cuento "Las notas que duermen en las cuerdas". Es inevitable la reminiscencia de Julio Cortázar -descubierto por Bryce, con deslumbramiento, en el periodo que escribía Huerto cerrado-, en particular del libro Historias de cronopios y de famas (1962), que contiene la sección 
A lo largo del relato, esta vez narrado con aséptica objetividad salvo dos acotaciones finales-, solo vemos al personaje cumplir con sus ocupaciones bizarras: tocar timbres y correr, barrer el muladar con un palo de escoba, lanzar el lápiz a las nubes y esperar; hasta que decide trepar el muro para observar el paso de un desfile escolar. Ante la pared -que es la del manicomio-, el narrador hace una sutil observación:

Él había visto esa puerta. Esa puerta estaba abierta, y por allí entraban las visitas, o sabe Dios quién. Cualquiera podía entrar por esa puerta...

Cualquiera, pero no el personaje en cuestión. Él queda al borde, sentado simbólicamente en el derrame del muro que divide el mundo de la cordura del mundo de la locura. Bien visto: de las categorías de la realidad y de la memoria. Desde lo alto, al final del relato, el personaje es ahora un espectador privilegiado que celebra el espectáculo -¿también la culminación del libro?-, mientras el narrador nos revela su identidad y sus urgencias y compromisos con la realidad:

... un-dos-un-dos-un-dos, gritaba Manolo, aplaudiendo al mismo tiempo, y en una de ésas logró ver la hora de su reloj, y pensó que en su casa estarían empezando a almorzar, y que tal vez debería volver, sería mejor si volviera, porque allá, en su casa, alguien podría preocuparse...

Vuelto a la normalidad, la "extraña diversión" es un entretenimiento que revela la conducta deliberada y absurda de Manolo, pero que encierra el sentido de un personaje confinado al limbo de su existencia. Desde el primer cuento de Huerto cerrado hasta este último, incluso desde antes -el "cuento" de la pérdida de los originales- la descolocación del protagonista se presenta a través de un "yo" altamente sensible y fracturado. Son por estas fisuras que nace y se expande la particular escritura del autor, pues su proceso verbal es fiel al dictado de una memoria amplia y caprichosa:

Dueño de un toque de auténtico humor que no quita intensidad al pathos, -escribe Gabriela Coulson en su ensayo-, Bryce se sumerge

“Ocupaciones raras". Leamos un fragmento: “Qué maravillosa ocupación ir andando por el bulevar Arago contando los árboles, y cada cinco castaños detenerse un momento sobre un solo pie y esperar que alguien mire, y entonces soltar un grito seco y breve, y girar como una peonza, con los brazos bien abiertos...". 
al pasado para extraer de él unas pocas situaciones bien seleccionadas que enmarcan lo que es significativo en su pequeño mundo: la memoria del individuo ${ }^{12}$.

Revisados los doce cuentos de Huerto cerrado, es palpable la gravitación del protagonista -su peculiar proceso de aprendizajesobre aspectos relacionados a la acción o el ambiente narrativos. Como en La casa de cartón, el discurso emerge fundamentalmente de la percepción íntima del personaje central, cuya aguda conciencia, paradójicamente, lo libera de su eje. "Es una actitud literaria -afirma el estudioso Joaquín Marco-, una forma retórica que implica sabiduría..."13. Nos interesa, por consiguiente, detener nuestro estudio en esta condición de Manolo de estar fuera de lugar, de vivir descolocado ante un mundo que castiga su hiperestesia y fragilidad. Sobre todo bajo dos maneras de dominación: de clase social y de género.

Atendiendo al filósofo francés Michel Foucault, quien advierte que lo más importante no es determinar el concepto de poder sino cómo se ejerce y quiénes lo ejercen, entendemos el poder como el universo de relaciones en el que se está y se constituye el sujeto ${ }^{14}$ y que todas las relaciones sociales son, en menor o mayor grado, relaciones de poder. En este sentido, Alfredo Bryce construye en Huerto cerrado un autor implícito que muestra con ironía el comportamiento de una clase social media, que poco había sido retratada por nuestra narrativa.

Como el personaje narrador de La casa de cartón que registra el derrumbe de la rancia aristocracia, Manolo pertenece a una clase media amable y desde allí observa al grupo social dominante/agresivo: la gran burguesía de los años sesenta. Las relaciones de poder a nivel de clase se concentran en el relato "Con Jimmy, en Paracas", donde el protagonista constata el poder de la burguesía limeña y, así mismo, el servilismo de su propio padre que lucha por mantenerse cerca de este nivel:

12 Coulson, Graciela. “Ser y parecer en el nuevo realismo: Bryce Echenique o la apoteosis de la memoria". El Urogallo 35, 1975, pp. 95-101.

13 Marco, Joaquín. “Permiso para vivir". Oiga. Lima, 19 de abril de 1993, pp. 55 y 56.

14 Lanceros, Patxi. Avatares del hombre. El pensamiento de Michel Foucault. Bilbao: Universidad de Deustuo, 1996. 
Ahora ya sé que sólo es el hombre más bueno de la tierra... en realidad se muere de miedo de sus jefes; esos jefes que lo quieren tanto porque hace siete millones de años que no llega tarde ni se enferma ni falta a la oficina...

La relación del padre con sus jefes es de temor a ser rechazado del medio al cual ansía ingresar, bien a través del reconocimiento laboral o de sus hijos, a quienes educa en escuelas inglesas como hacen sus jefes. La subordinación del padre frente a ellos y luego hacia Jimmy -hijo de uno de los directores de la compañía-, destruye la imagen que Manolo tiene de su padre. Si en algún momento fue su modelo masculino, después de este develamiento paterno él entra en una necesidad de un nuevo modelo que lo ayude a reafirmar su identidad masculina. Inicia una lucha interna por negar las virtudes de su padre, pues se acercan más a cualidades femeninas: pasividad, docilidad, parquedad, diligencia. Entonces Manolo procura construir su identidad en oposición -con los amigos, el profesor-, pero sin conseguirlo cabalmente, como lo demuestra el libro.

En los siguientes relatos encontramos a Manolo inmerso en su grupo de pares, relacionándose con chicos y chicas. Así descubre la amistad, el amor, el sexo. Tanto las relaciones de género -varones y mujeres-, como las relaciones intragénero implican relaciones de poder y permiten definir la masculinidad. Así ocurre con el protagonista y Jimmy, compañero de colegio, en el cuento "Con Jimmy, en Paracas". Una primera lectura nos lleva a pensar en una atracción homosexual, sustentada en la descripción casi femenina que hace el narrador al afirmar que "Jimmy era de una belleza extraordinaria: rubio, el pelo en anillos de oro, los ojos azules achinados, y esa piel bronceada todo el año...". Sin embargo Jimmy demuestra lo contrario, pues posee actitudes de hombre adulto: fuma, bebe alcohol, maneja auto, ordena y recibe reconocimiento social. Su aparente inclinación sexual es parte del proceso de identidad masculina -fetichismo fálico de los adolescentesy expresa también su posición de dominación social, expresada en la conducta que los sociólogos denominan "seguridad de clase".

Manolo huye de Jimmy por temor a que su territorio íntimo -su cuerpo- sea expuesto a ritos que desconoce, pero que no tardará en descubrir y participar de ellos. En "El camino es así" el espacio de socialización se amplía: es el colegio. Un colegio de varones, regentado 
por curas encargados de la formación académica y espiritual. Aquí los alumnos participan en una competencia ciclística y deben demostrar su valor -o cobardía- mediante el esfuerzo físico; uno de los requisitos de la hombría. El relato evidencia las redes de solidaridad que tejen los varones ante un evento que evalúa el proceso de su masculinidad, por eso Manolo sabe que debe superar la prueba. Pero él, aunque pródigo con la imaginación, es físicamente incompetente:

“Te prometo que sólo hasta Vitarte. Te lo juro. En Vitarte se acaba todo". Trataba de convencerse; trataba de mentirse, y sacaba fuerzas de su mentira convirtiéndola en verdad. "Vamos cuerpo". Pedaleaba y Vitarte no aparecía nunca.

La evolución del amor va de la mano con el desarrollo físico y psicológico del personaje adolescente. Desde su grado cero, en el momento que descubre que el mundo no gira solo alrededor de sus pares, visibiliza al otro sexo como sujeto atrayente. Momento que puede percibirse en el cuento "Su mejor negocio", donde afirma su pertenencia a un grupo de pares determinado: los del colegio, no los del vecindario. Esta etapa marca una distancia social que se patentiza en el traje nuevo adquirido con la venta de su bicicleta. Traje que "alguien diría que era demasiado para sus catorce años, pero no era suficiente para su felicidad." La pequeña operación comercial implica un grado de madurez, realizada sobre todo para adquirir una prenda que otorgue seguridad de atraer la mirada de jovencitas de su edad y grupo social.

El amor adolescente es, cada vez menos, un amor romántico que idealiza y convierte al otro en un sujeto sublime y virtuoso. En los relatos "Las notas que duermen en las cuerdas" y en "Una mano en las cuerdas" Manolo experimenta cambios en su vida personal, es más sensible y reservado. En el primero, surge en Manolo un sentimiento protector hacia frágiles adolescentes, frente a los muchachos agresivos que las ven como un objeto o "producto alimenticio". Este rol lo hace sentir distinto, pero "yo no soy un héroe para dedicarme a darles la contra". A la vez que se siente terriblemente tímido para interactuar con ellas. Solo acude a verlas a la salida del colegio, pues apenas salen él da media vuelta y se marcha. Ritual que continúa, y culmina, en un cuento posterior.

En "Una mano en las cuerdas" ha superado este enfrentamiento y su angustia está ahora relacionada con las normas sociales de cómo 
dar el primer beso y las primeras caricias y efectuar los juegos de pareja. Son los ritos/las pruebas para afirmar su masculinidad frente a los amigos y la sociedad. Inflamado por el amor romántico, se expresa de Cecilia -su primera enamorada-como de una virgen:

La veía con su traje blanco y sus zapatos blancos... La adoraba mientras la miraba de perfil y comprobaba que su nariz era muy respingada y que tenía las manos muy blancas y limpias... "Es linda. Debe ser buenísima. Parece un pato".

Imagen que lo llena de ternura y respeto hacia ella. Esta relación es el modelo que marcará sus relaciones posteriores, por ser un amor inmaculado -los domingos van a misa, se confiesan-; otra vez Manolo alejado de lo vulgar de las conductas masculinas. Como cuando un amigo le pregunta si había "imaginado a Cecilia cagando" y él no reacciona, sino cuando escribe en su diario: "Esa grosería. La asquerosidad de ese imbécil".

Aunque nuevamente se advierte la solidaridad de los amigos -aquellos con experiencia amorosa aconsejan al novato-, las actuaciones de Manolo resultan imperfectas. Él desobedece o atenúa los consejos machistas, pues entiende que su enamoramiento -caballeroso y delicado- es diferente al amor común, con reglas y roles que hay que seguir:

Hoy le he cogido la mano por primera vez, sentí que uno de los más viejos sueños de mi vida se estaba realizando. Sin embargo, después sentí un inmenso vacío. Era como si hubiera despertado de un sueño. Creo que es mejor soñar. Me gustaría que las cosas vinieran con más naturalidad. Todavía me falta besarla. Según Carlos, debo besarla primero disimuladamente... ¿Hasta cuándo no podré quererla en paz?

La búsqueda de modelos masculinos lleva al joven, en ocasiones, a la cercanía e identificación con sus maestros. Es el caso de Manolo en "Un amigo de cuarenta y cuatro años". Mr. Davenhock es un hombre maduro -director del colegio-, "británicamente distinguido" y con modales refinados: es reservado, fuma en pipa, lee periódicos ingleses. Manolo lo percibe como un modelo masculino, no solo por sus cualidades sino por el trato que le ofrece al revelarle una pasada experiencia amorosa. Luego de la confesión, el sentimiento de ambos respecto del amor permite a Manolo aprender de las pasiones y que los actos socialmente femeninos -el llanto, el dolor- también son de los hombres: 
-Manolo- le dijo con voz temblorosa, es preciso que sepas, Manolo, que no debes ponerte en este estado. Cuando un hombre quiere a una persona, debe estar preparado... preparado. Aprender a sufrir sin que los demás se den cuenta...

El camino a la adultez no es tarea exclusiva de padres, maestros y amigos -responsables de la socialización masculina-, sino además del hallazgo de vías paralelas y/o marginales. Como en el relato "Yo soy el rey", que coloca a Manolo en el prostíbulo que era -hasta hace dos décadas- espacio obligado para la iniciación sexual. Pero el protagonista no desea de ese modo y, por consiguiente, no consuma el acto. Su amor virtuoso - Cecilia como imagen omnipresente- ha sido manchado con la escena envilecida del burdel. Esos sentimientos son guardados en reserva, pues para los amigos que lo acompañan su virilidad está comprobada socialmente. Manolo, en cambio, reafirma que no se acomoda a la doble moral de su sociedad.

Comprueba, además, que la mujer también puede pertenecer al mundo degradado -en oposición al mundo angelical de su grupo social- y que el hombre puede ser ridiculizado y rechazado a través de su sexualidad: la prostituta Nylon se burla de su ex pareja, calificándolo de rosquete -aunque él se autodenomine rey- y lo enfrenta a un hombre que la satisface sexualmente:

“¡Soy el rey, carajo!” Manolo alcanzó a verle la cara mientras Rudy lo arrastraba a través del salón, con dirección a la puerta. Era la cara de un loco, y sus cerdas brillantes y grasientas colgaban hasta el suelo. En ese momento, el negro dejó su vaso sobre el mostrador, y volteó ligeramente para mirar al cholo. Fue una mirada de desprecio.

En el cuento "El descubrimiento de América" Manolo es un estudiante universitario -condición que da poder y estatus- obsesionado por una muchacha exuberante, a quien seduce y abandona después de poseerla. Para lo cual despliega una serie de actitudes/valores que oscilan entre el amor y el cinismo. Desde su posición masculina, el protagonista clasifica a las mujeres en las que pueden ser amadas América, tonta y bonita- y las que no: las "Martas". Él validará su masculinidad a través de la conquista no solo amorosa, también sexual.

Aunque Manolo se repite varias veces la frase "como antes", su relación con América es una relación opuesta a su primera relación. La 
virtud y la bondad son desplazadas por la ingenuidad y la voluptuosidad del cuerpo de América. Por otro lado, los fines de esta conquista no se relacionan con el amor romántico anterior, están más del lado del ardor pasional y del cinismo. Después de poseer sexualmente a América, decide dejarla, contarle todo o desaparecer. En la desintegración nerviosa de su discurso, Manolo descubre que no era un acto de amor sino de comprobación de su virilidad. Y el lector, en definitiva, entiende que la virilidad -en tanto construcción social-, está alejada de los valores y sentimientos nobles del amor que animaron al personaje:

Te he querido tanto y ahora estoy tan triste y tú podrás decir que fue haciendo gimnasia y ya no volveré porque te hubiera querido. Antes antes antes. Mandar una carta. Explicarte todo. Desaparecer... Cobarde. Decirte la verdad. Sobre todo irme. Si supieras lo triste perdonarías pero nunca sabrás y esto también pasará... ${ }^{15}$

Llegados al final de este espléndido trayecto, no estaba descaminado su autor al pensar en "La vida es así" como título de un conjunto de cuentos que abordan -como señales de un difícil derrotero- el proceso de aprendizaje de un adolescente. Pero dos rasgos lingüísticos del título original -el verbo en presente y el modo imperativo-, no hubieran concordado con el tono nostálgico de los relatos. Más bien el título definitivo del conjunto cobra una mayor dimensión: el espacio de cultivo (la pubertad/la adolescencia) pertenece al pasado y ha sido irremisiblemente clausurado. Por lo tanto, el productor del texto ha sido expulsado de ese "huerto cerrado"/de ese edén. ${ }^{34}$ Solo los devaneos de la memoria (la reflexión, la nostalgia, la imaginación) pueden recuperarlo para la literatura: único acto creador que redime la existencia de Manolo. De este personaje entrañable y desquiciado, como dice Bryce de sí mismo: "siempre entre dos sillas con el culo en el suelo".

15 Recuerdo haber leído que Bryce, además de mencionar que Ribeyro "le puso el título" (conferencia en la Universidad de Texas, 1982), dice que esta es una frase bíblica, tomada de El cantar de los cantares. 
